\title{
CARACTERIZAÇÃO DOS ELEMENTOS FÍSICOS DA BACIA DO CÓRREGO SANTO ANTÔNIO (RIO CLARO/SP)
}

\author{
Characterization of the physical elements from the \\ Córrego Santo Antônio Basin (Rio Claro/SP)
}

\author{
Débora Aparecida Machi \\ Geógrafa formada na Universidade Estadual Paulista - Rio Claro \\ deboramachi@yahoo.com.br \\ Cenira Maria Lupinacci da Cunha \\ Professora Doutora do Departamento de Planejamento Territorial e \\ Geoprocessamento - Universidade Estadual Paulista, IGCE \\ cenira@rc.unesp.br
}

Artigo recebido para publicação em 02/10/2006 e aceito para publicação em 09/05/2007

RESUMO: O objetivo desta pesquisa foi caracterizar os elementos físicos da bacia do córrego Santo Antônio, buscando compreender a influência que a área de entorno dessa bacia exerce sobre a Floresta Estadual Edmundo Navarro de Andrade (FEENA). Para isto, foram elaboradas as cartas geomorfológica e de uso do solo, além da compilação de dados geológicos, pedológicos e climáticos. Essa influência foi avaliada em termos da dinâmica de remobilização de materiais provenientes das nascentes, que não pertencem a FEENA, e que se constituem, portanto, em área de uso agrícola. A análise das características físicas indicou que essa área é susceptível a ação dos processos morfogenéticos e que estes foram intensificados e acelerados pelo uso do solo ao redor das nascentes. Verifica-se, assim, a necessidade de se reavaliar esse uso e de se fiscalizar o cumprimento da própria legislação ambiental, no que se refere ao uso e ocupação do território, em fundos de vale.

Palavras-chave: sistemas, relevo, bacia hidrográfica

ABSTRACT: The objective of this research was to characterize the physical elements from the Córrego Santo Antônio basin, aiming to understand the influence of its surrounding areas towards the Edmundo Navarro de Andrade State Forest (ENASF). For this, we produced geomorphological and land use maps and compiled geological, soil and climatic data. Such influence was evaluated in terms of the dynamics of the transportation of the materials from the stream sources, outside of ENASF and over agricultural areas. The physical characteristic analyzes indicated that this area is sensitive to the morphogenetic processes and that they were intensified and accelerated by the land use surrounding the stream sources. Therefore, it is necessary to reevaluate the land occupation and to fiscalize the accomplishment of the environmental laws related to the land use in valleys.

Keywords: systems, relief, hydrographic basin 


\section{INTRODUÇÃO}

A Cartografia constitui-se em um instrumento de representação, correlação e análise imprescindível para o planejamento e gestão territorial. Neste contexto, a representação cartográfica do relevo tem papel relevante, visto que é sobre as feições geomorfológicas que se localizam e se desenvolvem as atividades humanas (Cunha, 2001).

Se as formas de relevo constituem o substrato físico das instalações humanas, estas também sofrem modificações causadas por tais instalações e respondem a tais alterações, muitas vezes, de forma agressiva (Cunha, 2001).

Casseti (1994 apud Cunha, 2001, p.1), ao referir-se a este problema, afirma que

(...) mesmo a ação indireta do homem, ao eliminar a interface - representada pela cobertura vegetal - altera de forma substancial as relações entre as forças de ação (processos morfodinâmicos) e de reação da formação superficial ou mesmo do substrato, implicando em desequilíbrios morfológicos, e muitas vezes tendo conseqüências geoambientais (movimentos de massa, boçorocamento, assoreamento...) que chegam a ser catastróficas.

A representação cartográfica do relevo pode fornecer informações que auxiliam na ocupação ou, em caso de ocupação já efetiva, pode identificar áreas potencialmente problemáticas no futuro.

Neste contexto, verifica-se a importância de se analisar tais feições a partir de unidades espaciais que contemplem as especificidades morfogenéticas do relevo. A concepção da bacia hidrográfica como “área de drenagem de um curso d'água ou de um lago” (Brasil, 1983, p.20), engloba princípios que atendem tal demanda. Esta unidade de terreno é um sistema aberto que recebe energia e massa na forma de água proveniente das precipitações atmosféricas e de sedimentos das vertentes, e perdem massa e energia através da água e sedimentos que são deslo- cados em direção aos cursos fluviais, lagos ou oceanos. Assim, a análise de relevo através da bacia hidrográfica se torna relevante por esta ser um sistema, no qual, se compreendido seu funcionamento, permite a previsão da evolução do modelado da área e saber o melhor modo do homem utilizá-la.

Segundo Cunha (1997), há um consenso, entre os pesquisadores que se dedicam à questão ambiental, de que a bacia hidrográfica constitui-se em uma unidade fundamental para o planejamento da paisagem. Sabe-se, entretanto, que o uso das terras é definido pelo homem e muitas vezes ultrapassam os limites da bacia, como é o caso da área deste estudo.

A área deste estudo inclui parte da Floresta Estadual Edmundo Navarro de Andrade (FEENA), uma unidade de conservação de uso sustentável que, conforme a Lei $n^{\circ} 9.985$ de julho de 2000, tem o objetivo básico de compatibilizar a conservação da natureza com o uso sustentável de parcela dos seus recursos naturais.

As nascentes dos cursos d'águas que cortam essa unidade de conservação, como é o caso da bacia do córrego Santo Antônio, localizam-se fora desta, por isto é necessário saber a influência que estes corpos exercem sobre a unidade, para que a partir das informações da dinâmica desta bacia hidrográfica possa haver um uso sustentável de seus recursos naturais.

Com o presente trabalho, pretende-se caracterizar os elementos físicos da bacia do córrego Santo Antônio, objetivando entender a real influência da área de entorno sobre a Floresta Estadual Edmundo Navarro de Andrade. Esta influência será avaliada em termos da dinâmica de remobilização de material proveniente das nascentes que não pertencem a FEENA e que estão sobre áreas de uso agrícola intensivo.

\section{ÁREA DE ESTUDO}

A bacia do córrego Santo Antônio situa-se a leste da área urbana de Rio Claro, entre 22022’04" e $22^{\circ} 26^{\prime} 01^{\prime \prime}$ de latitude sul e $47^{\circ} 27^{\prime} 42^{\prime \prime}$ e $47^{\circ} 35^{\prime} 0 l^{\prime \prime}$ 
de longitude oeste, posicionando-se na região centro- leste do Estado de São Paulo (Figura 1).

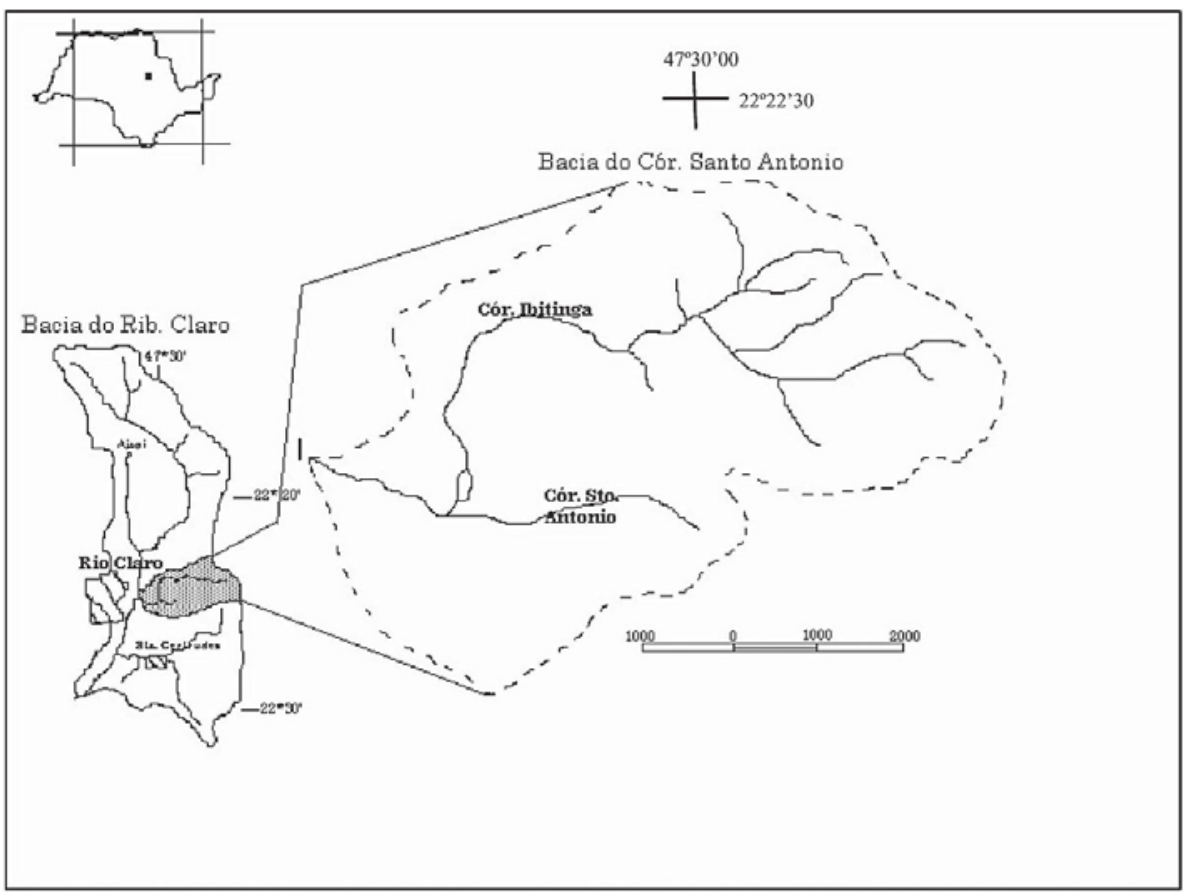

Figura 1. Esboço esquemático da localização da área de estudo.

Fonte: Cunha (1997, p.95).

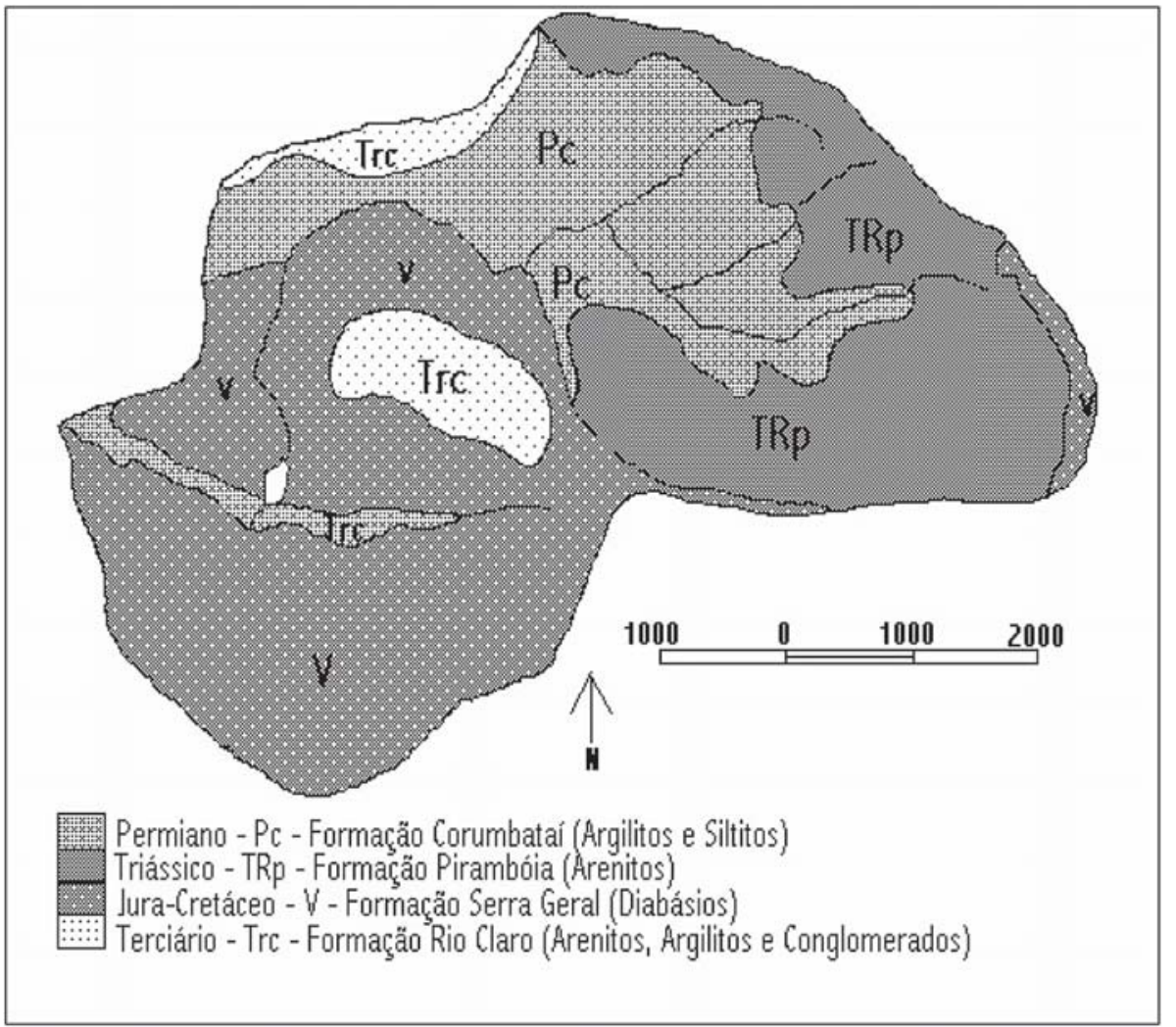

Figura 2. Esboço geológico da bacia do córrego Santo Antônio.

Fonte: Cunha (1997). 
Com relação às características geológicas da bacia do Córrego Santo Antônio (Figura 2), estas estão vinculadas às Formações Corumbataí, Serra Geral, Pirambóia e Rio Claro (São Paulo, 1988 apud Cunha, 1997).

A Formação Corumbataí, datada do Permiano, ocorre no setor de vale do Córrego Santo Antônio, onde se encontra recoberta por Latossolos Roxo. Também se faz presente em uma faixa contínua que abrange a média bacia, onde sua decomposição dá origem a Podzólicos Vermelho Amarelo,
Unidade Serrinha, atualmente denominados de Argissolo Vermelho Amarelo (Figura 3).

A Formação Pirambóia, datada do Triássico, ocorre nos setores NE, E e SE, estando posicionada entre a Formação Corumbataí e uma faixa estreita da Formação Serra Geral, no extremo leste da área de estudo. Tal formação encontra-se recoberta por variadas coberturas pedológicas, as quais vinculamse tanto a Latossolos Roxo, como a Podzólicos Vermelho Amarelo das unidades Serrinha, Santa Cruz e Olaria.

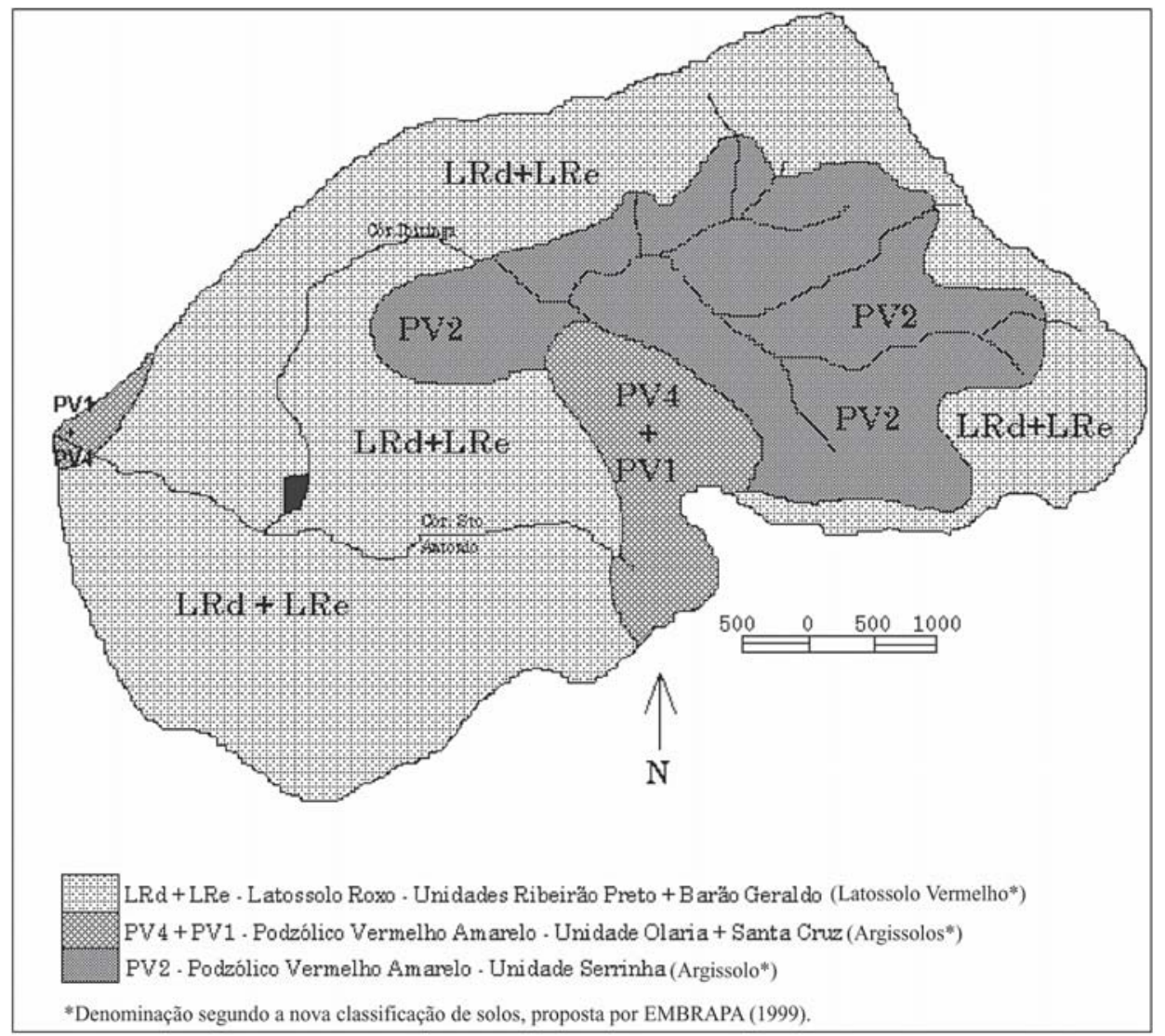

Figura 3. Esboço dos tipos de solo da bacia do córrego Santo Antônio.

Fonte: Adaptado de Cunha (1997).

A Formação Serra Geral se faz representar por diabásios, resultantes dos derrames ocorridos no Jurássico-Cretáceo, localizados no interflúvio dos córregos Ibitinga e Santo Antônio, entre este e o limite sul da bacia, assim como em uma faixa estreita no extremo leste da área enfocada. Segundo IPT (1981), vários fatos, como a uniformidade e extensão dos derrames e a preservação da morfologia local de dunas, comprovam que tal formação originou-se do “extravasamento rápido de lava muito fluída” e que, durante este evento, houve a manutenção das condições desérticas.

Sobre tal formação, desenvolvem-se Latos- 
solos Roxo, originários da decomposição do diabásio, o que, segundo Oliveira e Prado (1984), atribuemlhes características próprias, como altos teores de óxido de ferro e titânio. Os autores citados esclarecem que estes ocorrem, geralmente, em áreas onde os cursos fluviais esculpiram as rochas cretáceas e póscretáceas,_aflorando os basaltos e diabásios. Convém destacar que, no caso da bacia do córrego Santo Antônio, a área recoberta pelo Latossolo Roxo ultrapassa os limites do diabásio, recobrindo também outras litologias. O mesmo ocorre no caso das demais formações, fato que pode ser explicado pela incompatibilidade de escalas das fontes relativas aos dados pedológicos e geológicos aqui apresentados.

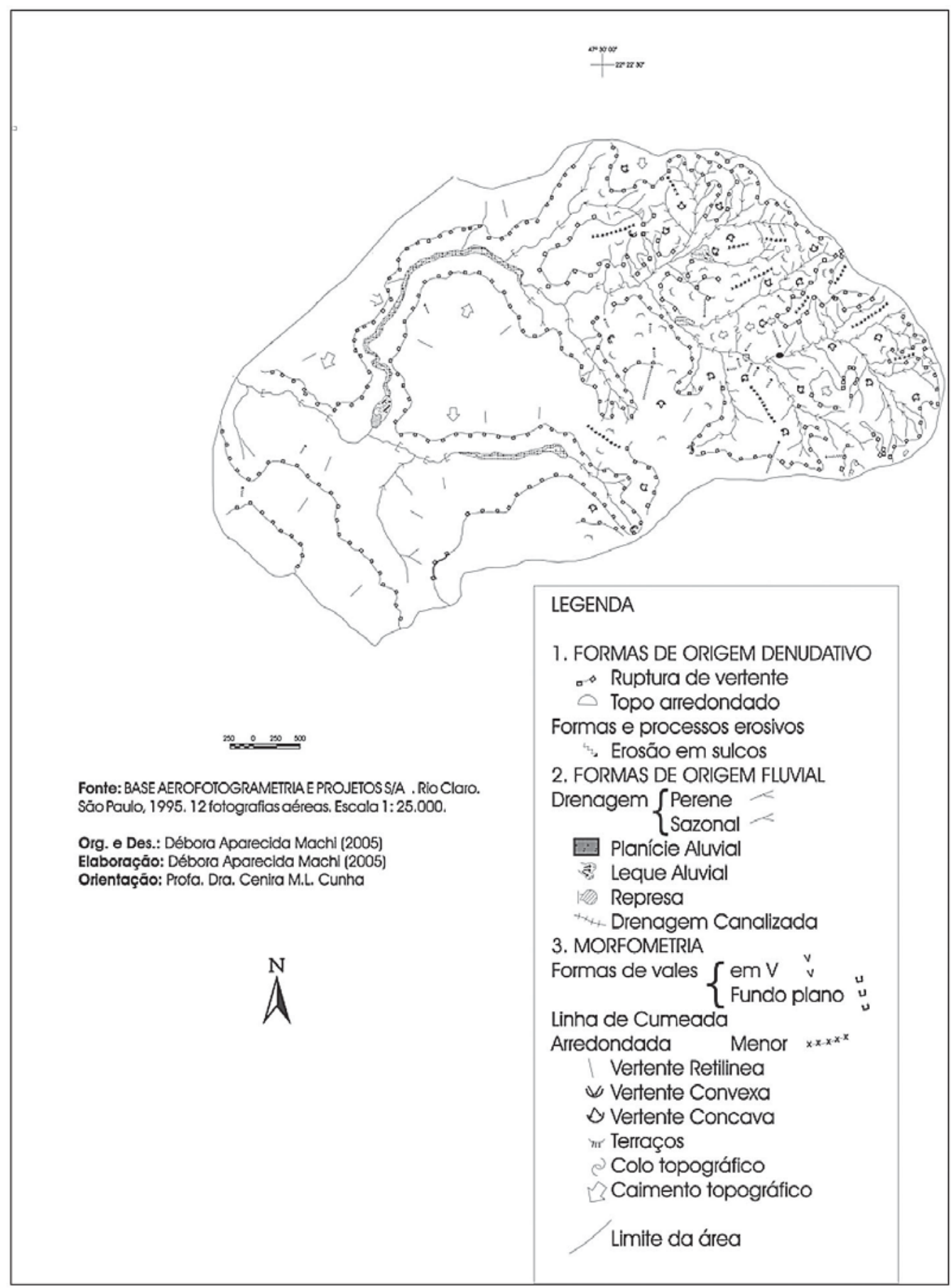

Figura 4. Carta geomorfológica da bacia do córrego Santo Antônio. 
O Latossolo Roxo, unidade Ribeirão Preto, de acordo com Oliveira e Prado (1984, p. 29), caracteriza-se como um solo eutrófico, horizonte A moderado e textura muito argilosa ou argilosa. Estes autores afirmam ainda que, devido às suas ótimas características físicas e químicas, verifica-se um intenso uso agrícola o que, em muitas áreas, torna difícil a descrição da camada superficial já que a estrutura original foi destruída por tal atividade.

A unidade Barão Geraldo diferencia-se da Ribeirão Preto devido ao seu caráter distrófico, o que implica em menor saturação por bases. Por este motivo, a diferenciação só é possível através de análises laboratoriais, implicando, no processo cartográfico, em dificuldades na individualização destas unidades, fato que levou, segundo os autores citados, ao mapeamento destes como associação. Convém lembrar que, no caso de associações, o primeiro solo indicado, neste caso o Ribeirão Preto, ocupa 60\% da área, enquanto que o segundo, unidade Barão Geraldo, 40\% da área mapeada.

Tais características do substrato rochoso e dos solos dão origem a formas de vertentes variadas (Figura 4). Contudo, constata-se que aquelas vertentes vinculadas à ocorrência da Formação Serra Geral e, conseqüentemente, dos Latossolos Roxo, apresentam, com maior freqüência, formas retilíneas, caracterizadas por grande continuidade espacial. Tais formas também ocorrem sobre outras litologias, porém, nestes casos, são mais fragmentadas e com menor extensão.

As vertentes côncavas apresentam maior concentração no setor leste da bacia que corresponde ao setor de nascentes do córrego Ibitinga, tributário da margem direita do córrego Santo Antônio. Estas vertentes, geralmente, caracterizam-se por concentrarem água, dando origem, na maioria das vezes, a canais fluviais de primeira ordem. Já as formas convexas vão ocorrer em diversos setores da bacia, não apresentando grande continuidade espacial, visto que se encontram entrecortadas pelas outras formas já descritas.

\section{ABORDAGEM METODOLÓGICA}

A abordagem metodológica para o estudo da área baseou-se nos princípios que regem a Teoria Geral dos Sistemas aplicados à ciência geográfica. Os sistemas funcionam executando processos e visam a obtenção de determinadas respostas, como afirmaram Thornes e Brunsden (1977, apud Christofoletti, 1979, p.1), que conceberam o sistema como um "conjunto de objetos e atributos e das suas relações que se encontram organizados para executar uma função particular”. Já para Cowan (1963, apud Howard, 1973, p. 4), um sistema "é composto de elementos (objetos), seu estado instantâneo e interrelações, estando sujeito a modificações através do tempo". Portanto, nota-se que, em um sistema, existe uma relação entre objetos e seus atributos para executar uma função particular, que o modificará através do tempo.

Ao estudar a Geomorfologia, verifica-se que é impossível compreender o relevo sem considerar os fluxos de matéria e energia. As formas de relevo são frutos da interação da estrutura geológica, do clima atual e passado e, atualmente, da atividade antrópica, cujas relações interferem nas características pedológicas e na cobertura vegetal. A visão da Teoria Geral de Sistemas possibilita estabelecer e analisar tais inter-relações, tanto como compreender os vínculos de dependência entre esses fatores.

Os sistemas podem ser classificados conforme critérios variados. Para a análise geomorfológica, os mais importantes são o critério funcional e o da composição integrativa. Este estudo encontra respaldo metodológico no critério funcional, pois a bacia hidrográfica é uma unidade passível de ser entendida como um sistema aberto. Este tipo de sistema mantém relações com os demais sistemas do universo no qual funcionam através de constantes trocas de energia e matéria (Christofoletti, 1991). Considerando-se os critérios de complexidade da composição integrativa, Chorley e Kennedy (1971, apud Christofoletti, 1979) propuseram uma classificação estrutural e distinguiram 11 sistemas: morfológicos, em seqüência, processo-resposta, contro- 
lados, automantenedores, plantas, animais, ecossistemas, homem, sistemas sociais e ecossistemas humanos.

Na classificação estrutural, este estudo possui respaldo metodológico dos sistemas processoresposta. No sistema processo-resposta, pode-se "identificar as relações entre processo e as formas que dele resultam, caracterizando a globalização do sistema" (Christofoletti, 1993, p.6-7). Estes aspectos foram avaliados na correlação dos dados geomorfológicos, geológicos, climáticos e pedológicos e na carta geomorfológica, visto que, ao analisar a forma do relevo na fotografia aérea, inferem-se o processo ocorrente na área.

A seguir, são apresentadas os principais aspectos teóricos e metodológicos relacionados com a elaboração de três cartas temáticas desse estudo.

\section{Carta Geomorfológica}

As cartas geomorfológicas "constituem em documentos de alta complexidade, devido à grande quantidade de informações registradas, as quais abarcam desde a estrutura geológica, cronologia, morfografia, até características morfométricas da área” (Cunha, 2001). Procura-se, assim, em um único documento cartográfico, registrar características de relevo relacionadas ao sistema morfológico e processo-resposta. Para Verstappen e Zuidam (1975), o objetivo de um levantamento geomorfológico é obter uma imagem concisa e sistemática do relevo e dos fenômenos que estão ligados a este.

Neste trabalho, a carta geomorfológica teve, como orientação, a proposta do "International Institute for Aerial Survey and Earth Sciencies” (ITC, Holanda) (Verstappen e Zuidam, 1975). Esta proposta de levantamento geomorfológico é uma técnica analítica que compreende os aspectos morfométricos, morfográficos, morfogenéticos, morfocronológicos, litológicos e morfológicos.

Segundo Verstappen e Zuidam (1975), o mapa geomorfológico pode ser de três tipos: mapas preliminares, elaborados antes do trabalho de campo, com base somente na interpretação de fotografias aéreas; mapas com fins gerais, resultados de investigações geomorfológicas puras; e mapas com fins específicos, produtos de investigações geomorfológicas aplicadas. Podem ser de morfoconservação ou hidromorfológicos.

Para este trabalho, foi confeccionado um mapa para fins gerais, com ênfase nos dados morfográficos considerados essenciais para atender os objetivos dessa pesquisa.

Para a confecção da carta geomorfológica foram realizadas as seguintes etapas:

1. Foto-interpretação: foram utilizados pares estereoscópicos de fotografias aéreas na escala 1:25.000, datadas de 21 de junho de 1995. Para o mapeamento das feições geomorfológicas, utilizouse a simbologia de Verstappen e Zuidam (1975), na qual os símbolos são coloridos de acordo com a sua origem. Assim, as formas de origem denudativo foram mapeadas com símbolos de cor marrom, as de origem fluvial de azul escuro e as morfométricas de cor preta. Neste artigo, este mapeamento é apresentado em tons de cinza. Também foram utilizados os símbolos dos tipos de vertentes (retilínea, côncava e convexa) e terraços de cultivo das cartas de morfoconservação e, das cartas hidromorfológicas, o símbolo que representa as represas. A área de estudo apresenta algumas feições não abordadas por Verstappen e Zuidam (1975), por isto também foram utilizadas simbologias de Tricart (1965) referentes ao caimento e colo topográfico. Estes procedimentos possibilitaram uma análise mais detalhada do relevo.

2. Trabalhos de campo e edição da carta: após a fotointerpretação e a montagem de uma carta preliminar, foram realizados trabalhos de campo para reambular os dados mapeados. A carta foi editada através do programa Corew Draw 11.

\section{Carta de Uso do Solo}

A carta de uso do solo foi elaborada através 
da interpretação de pares estereoscópicos de fotografias áreas de escala 1: 25.000, datadas de 21 de junho de 1995. Para a realização da referida fotointerpretação, analisou-se os elementos de tonalidade, textura, forma da parcela, dimensão da área cultivada e arranjo espacial, como recomendam Ceron e Diniz (1966). Através deste documento cartográfico, verificou-se que, na área de estudo, ocorrem as seguintes categorias de uso do solo: mata, pastagem, cana-de-açúcar, cultura anual, área urbana e reflorestamento.

\section{Dados geológicos, pedológicos e climáticos}

Esses dados foram compilados do trabalho realizado por Cunha (1997) na mesma área de estudo.

\section{ELEMENTOS FÍSICOS: APRESENTAÇÃO E DISCUSSÃO}

Convém ressaltar a presença de uma nítida diferença nas formas geomorfológicas registradas nos setores que têm a presença da Formação Serra Geral daquelas cujas litologias vinculam-se à Formação Corumbataí. Neste contexto, nas áreas onde se encontram presentes o diabásio, verifica-se uma menor quantidade de rupturas topográficas. Já no setor leste, área das nascentes dos córregos Ibitinga e Santo Antônio, que tem como substrato rochoso a Formação Corumbataí, apresenta uma maior dissecação do relevo, expressa pelas inúmeras rupturas topográficas, canais pluviais e sulcos erosivos, identificados também através da reambulação em campo. A presença de leques aluviais comprova a remobilização de material existente neste setor, demonstrando a fragilidade deste aos processos erosivos. No setor NE, pode-se constatar a presença de colos topográficos que sugerem o avanço dos processos denudacionais e que podem, no futuro, gerar o rompimento destes topos internos.

A fragilidade demonstrada pela área, principalmente no setor abrangido pela Formação Corumbataí, inspira cuidados em relação à conservação do solo. Tal preocupação torna-se ainda maior quando se constata a intensa dinâmica pluvial dominante na área (Figuras 5 e 6).

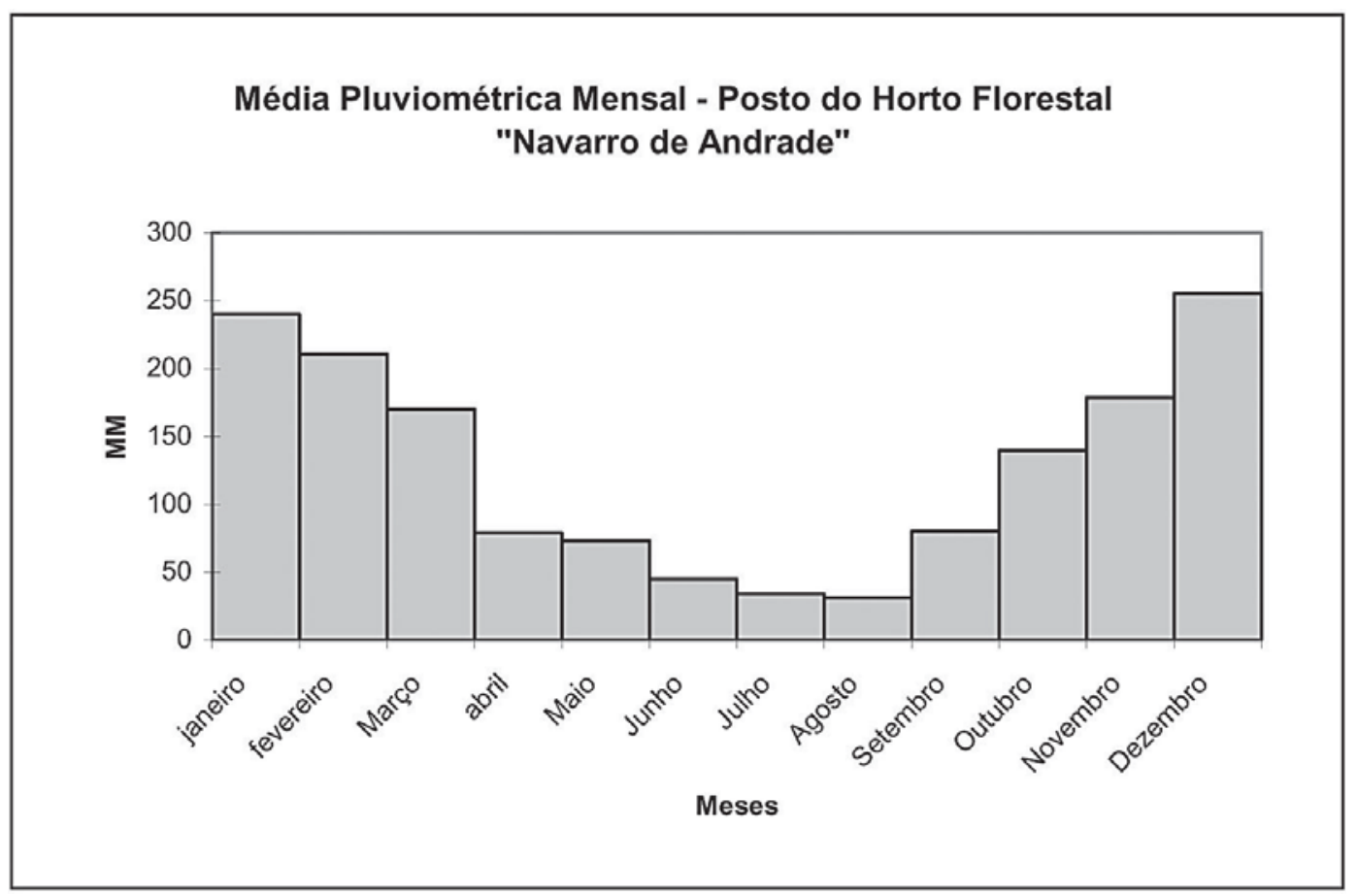

Figura 5. Média pluviométrica mensal do período de 1961 a 1995.

Fonte: Cunha (1997). 


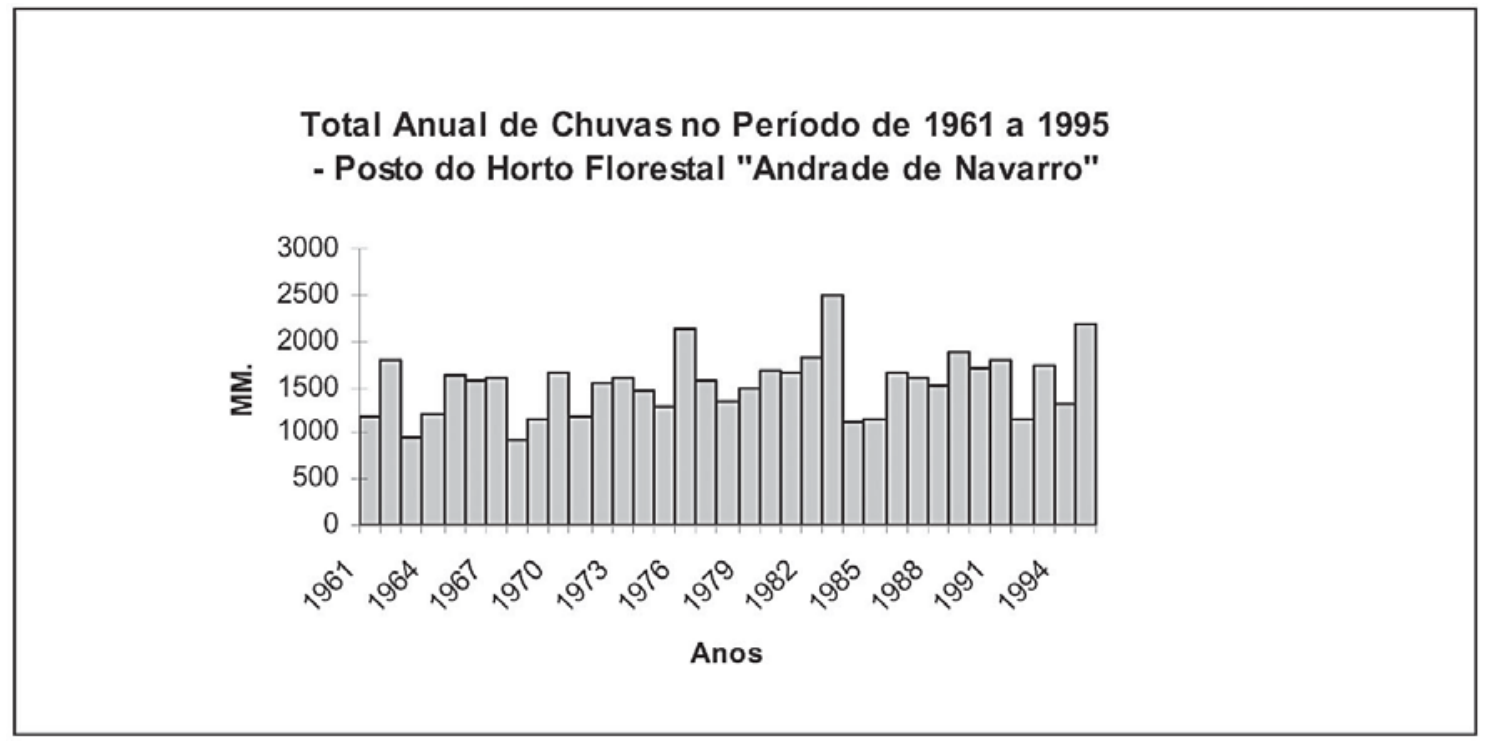

Figura 6. Total anual de chuvas, no período de 1961 a 1995, do posto pluviométrico do Horto Florestal "Navarro de Andrade".

Fonte: Cunha (1997).

A média pluviométrica anual calculada com base nos dados para o período de 1961 a 1995 é de $1.536 \mathrm{~mm}$; desse total anual, verifica-se uma maior concentração de chuvas entre os meses de setembro e março, correspondendo ao período mais quente do ano (Cunha, 1997).

Esta dinâmica pluvial exige um uso da terra coerente com tais características físicas registradas. Contudo, observa-se uma intensa utilização da agropecuária na área (Figura 7) e que, mesmo com medidas preservacionistas (terraceamentos), não conseguem conter os processos de dissecação do relevo (Figura 8). Estas formas de contenção erosiva comprometem também as formas das vertentes, tornando difícil a avaliação da dinâmica do escoamento pluvial nesta área.

Cunha (1997), em seu estudo sobre a bacia hidrográfica do córrego Santo Antônio, analisou o cenário do uso do solo no ano de 1972. Verificou-se a existência de um grande setor cujo uso do solo é o reflorestamento da FEENA; neste setor, localiza-se a maior parte dos Latossolos Roxos existentes na bacia. Trata-se de uma área cujo uso do solo se manteve o mesmo nos períodos analisados, sendo assim, a atuação dos processos morfogenéticos é minimizada pelo seu uso. Porém, encontram-se evidências da intensificação dos processos de remobilização de materiais no setor leste, através da presença de leques e planícies aluviais. Além disso, no interflúvio entre o Córrego Santo Antônio e Ibitinga, constatou-se, segundo o Instituto Florestal (2005), a presença de falhamentos e de grande complexidade litológica. Dessa forma, a manutenção da vegetação é essencial para a contenção dos processos morfogenéticos.

Em 1972, segundo Cunha (1997), verificavase que a cana-de-açúcar distribuía-se na forma de uma faixa quase contínua, localizada na média bacia, sendo interrompida localmente por pequenas áreas de pastagem, citrus, mata ou reflorestamento. No setor leste desta faixa, onde se encontram as principais nascentes do córrego Ibitinga, o uso do solo encontrava-se relacionado principalmente a pastagens, ocorrendo pequenas áreas de reflorestamento, cultura anual e mata. A mata ciliar encontrava-se preservada em poucos pontos, sendo tomadas pelas pastagens.

Através da comparação entre os dados de Cunha (1997) e aqueles apresentados na Figura 7, 


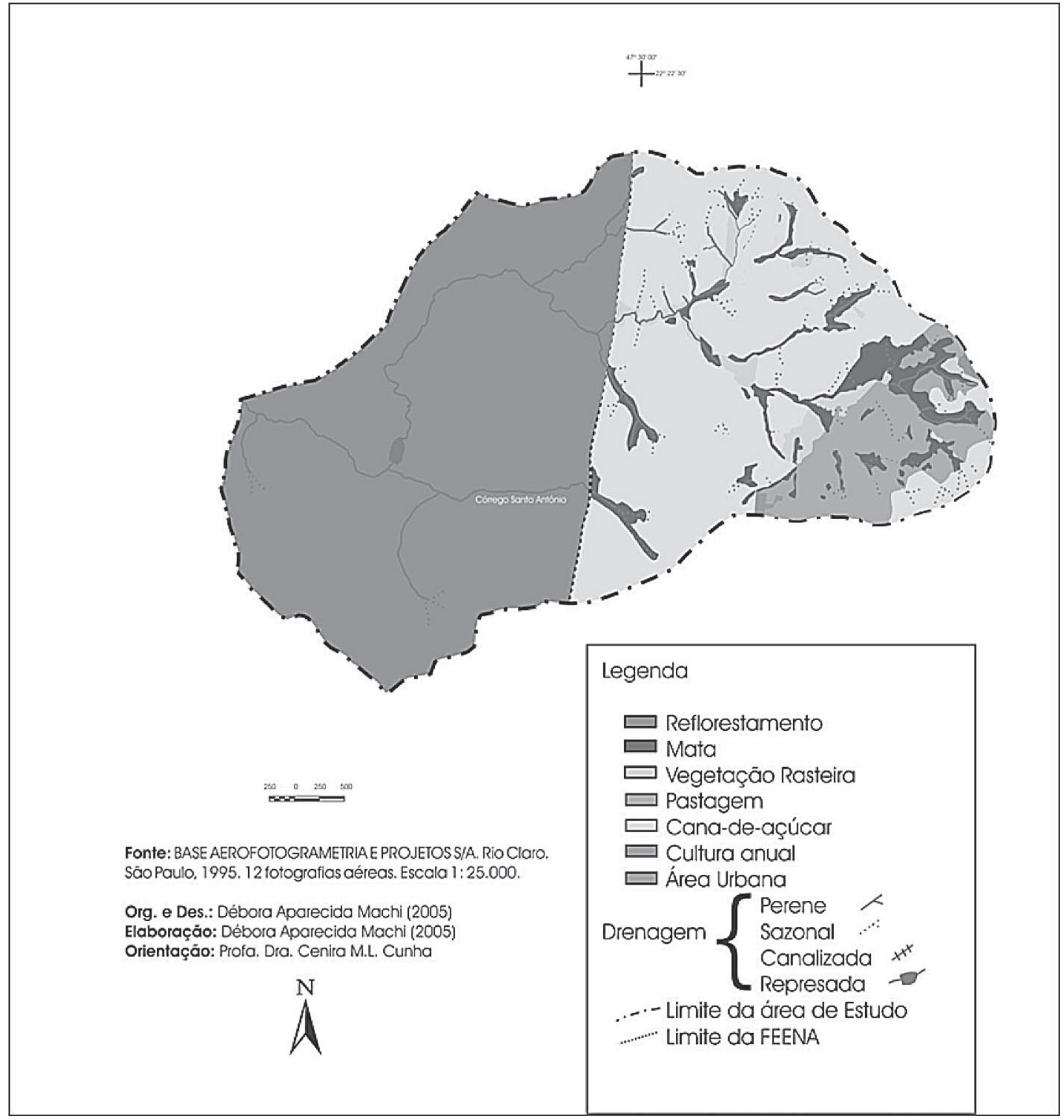

Figura 7. Carta de uso do solo da bacia do córrego Santo Antônio.

pode-se verificar a expansão da plantação canavieira sobre as pastagens. Hoje, constata-se que as plantações de cana continuam a se expandir, não apenas sobre as pastagens, mas inclusive sobre a mata ciliar. A mata ciliar encontra-se preservada apenas em algumas nascentes (Figura 9), estas são importantes para impedir que o material remobilizado das vertentes alcancem os cursos d’água.
Em situações em que tal mata encontra-se destruída, constata-se que o material remobilizado das vertentes atinge o leito dos rios, modificam a forma do vale, gerando processos de retomada erosiva, como foi observado em campo, no córrego Ibitinga. Esta drenagem, atualmente, busca aprofundar seu leito, entalhando os sedimentos depositados em fases anteriores, constituindo indício 


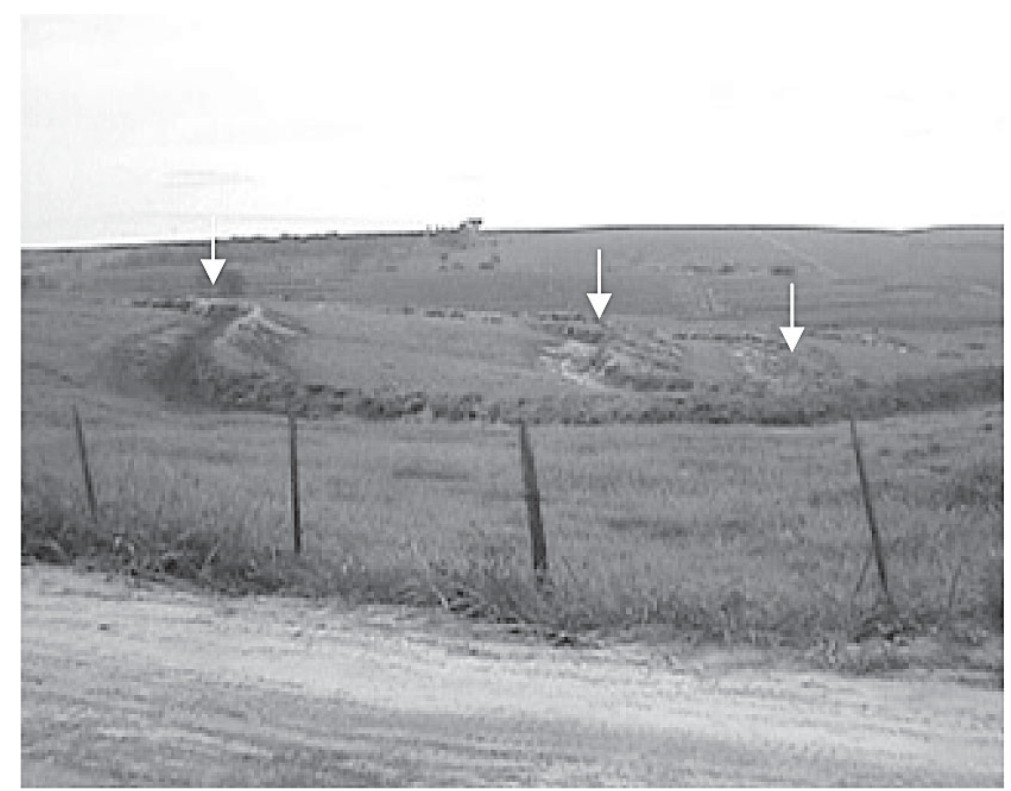

Figura 8. Terraceamento agrícola (setas), próximo ao curso do córrego Ibitinga (Machi, 2005).

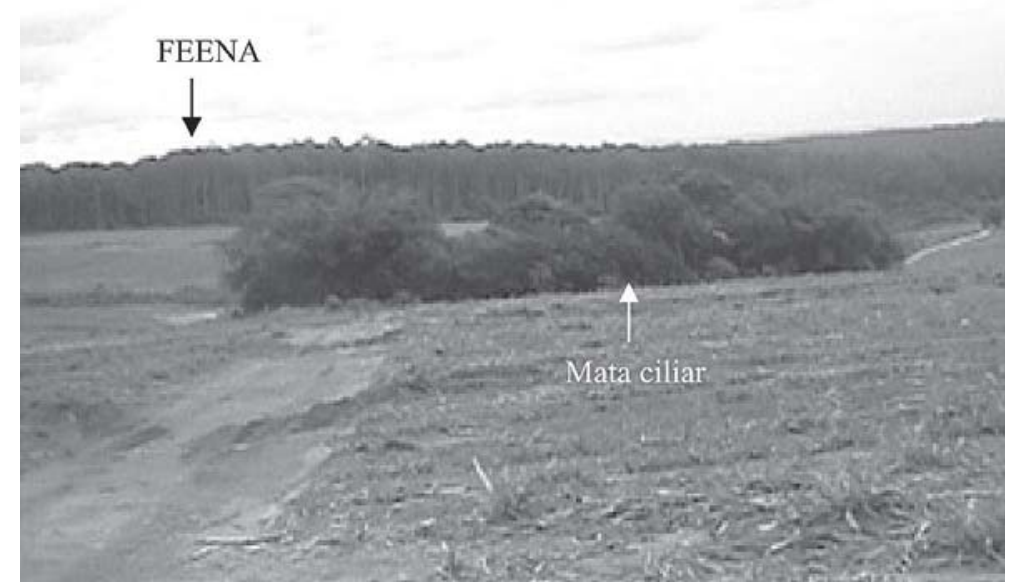

Figura 9. Mata ciliar preservada de uma das nascentes do córrego Ibitinga (Machi, 2005).

da retomada erosiva deste canal fluvial. No campo, constatou-se ainda a intervenção humana nas nascentes soterradas para construção de vias de transporte (Figura 10).

Esta utilização da área, aliada à fragilidade da formação litológica do setor ESE, inspira cuidados em relação à conservação do solo. Tal preocupação se torna ainda maior quando se constata a intensa dinâmica fluvial da área. Como se visualiza na Figura
11, a maior parte das nascentes vinculadas ao córrego Ibitinga tem sua origem sobre um degrau topográfico sustentado pela Formação Serra Geral, e, na seqüência de seu curso, atingem a Formação Pirambóia, constituída por material arenítico, de grande fragilidade erosiva. Estas características geológicas potencializam a velocidade do escoamento da água e implicam em contatos litológicos que indicam suscetibilidade a ação dos processos morfogenéticos, caracterizados por esta discordância erosiva. 


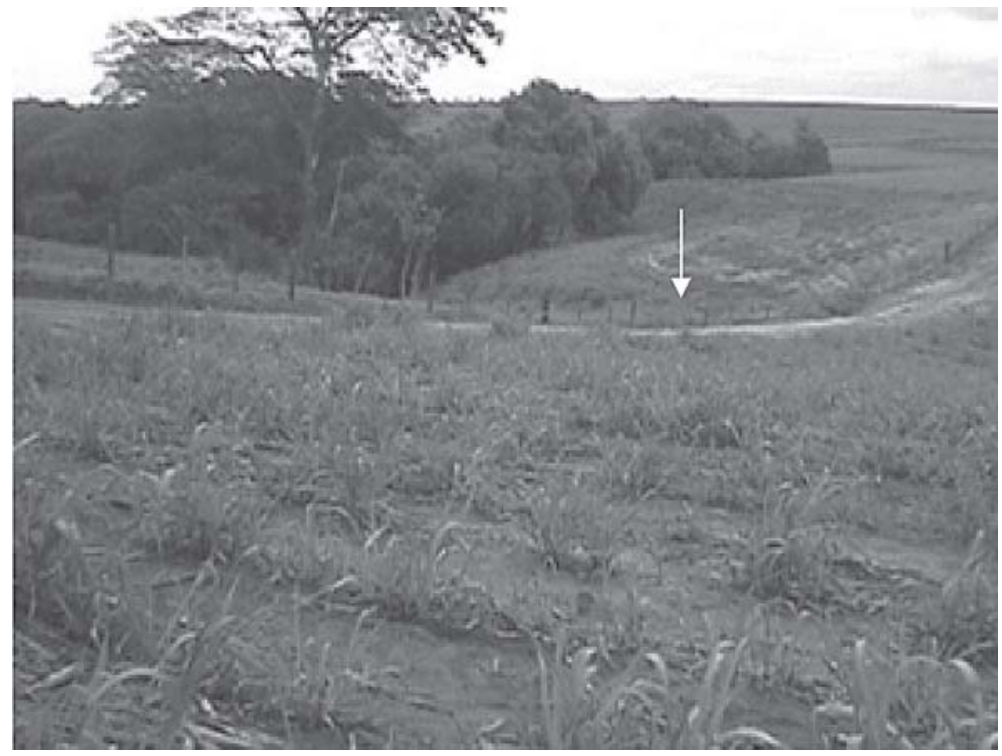

Figura 10. Soterramento de nascente (seta) do córrego Ibitinga (Machi,2005).

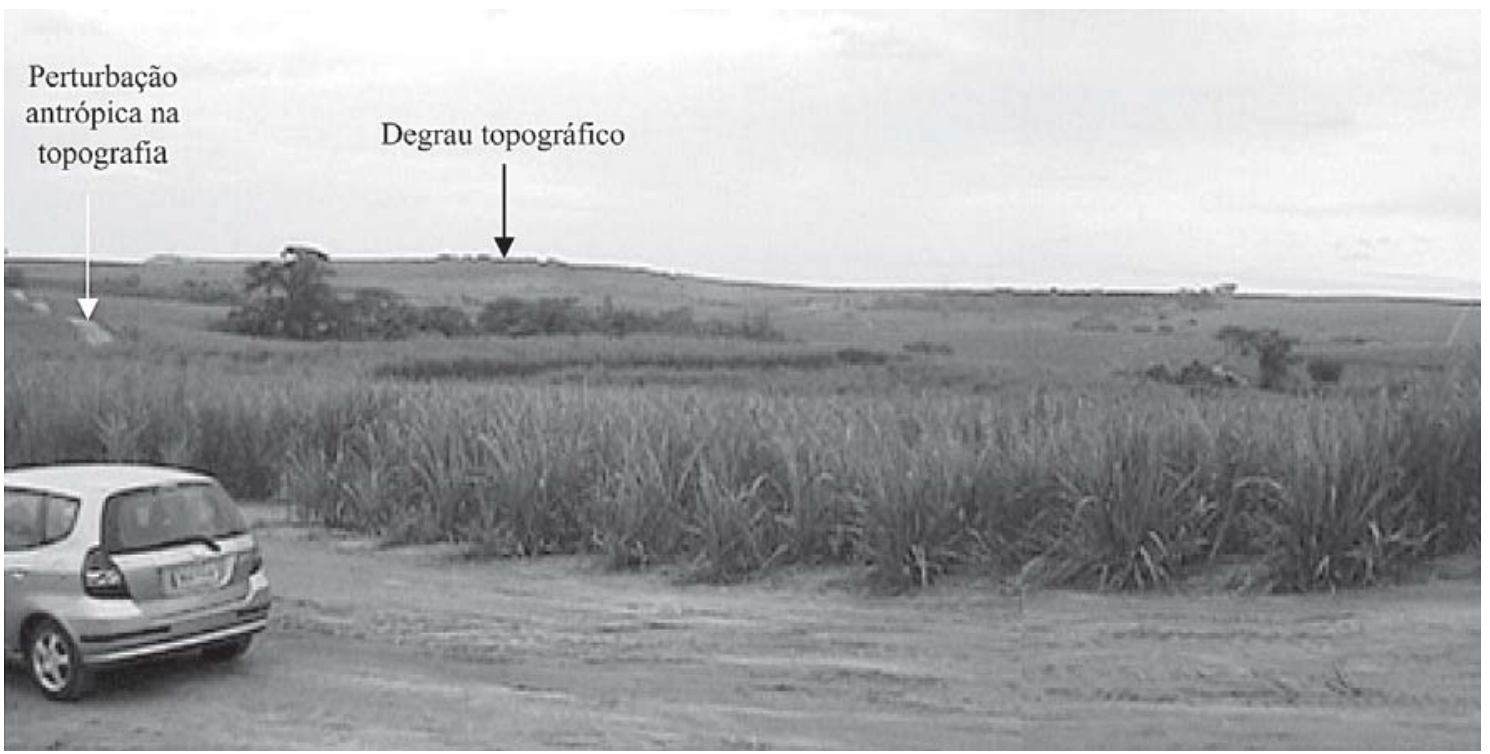

Figura 11. Degrau tipográfico, derrame basáltico, recortado por nascentes (Machi, 2005).

Enfim, as características físicas e o uso do solo sugerem a necessidade de maior precaução no uso da área para evitar problemas referentes à dinamização de tais processos, os quais trazem consigo problemas de assoreamento dos cursos fluviais e reservatórios, assim como a perda de fertilidade das terras. $\mathrm{O}$ assoreamento já pode ser verificado, por exemplo, no açude do córrego Ibitinga.

\section{CONSIDERAÇÕES FINAIS}

Através da caracterização dos elementos físicos, pôde-se constatar que a área analisada apresenta diversos contatos litológicos e uma dinâmica pluvial intensa, que quando aliada ao uso do solo, pode acelerar os processos morfogenéticos, como é o caso do setor leste da bacia do córrego Santo Antônio. 
A carta geomorfológica ressaltou a dinâmica erosiva instalada na área de estudo, ao demonstrar a dinamização da atuação dos processos morfogenéticos, principalmente no setor leste. A presença de rupturas topográficas por toda a área de estudo indica uma possível fragilidade erosiva. A presença de leques e planícies aluviais comprova a ocorrência de grande remobilização de sedimentos em direção à FEENA.

Na carta de uso de solo, observou-se uma intensificação das atividades agrícolas, principalmente com a expansão da lavoura da cana de açúcar, e, concomitantemente, a retração das áreas ocupadas pela mata ciliar na maior parte das nascentes. A fragilidade litológica aliada a este uso de solo vem acelerando os processos morfogenéticos da área.

Assim, verifica-se a necessidade de reavaliar este uso e de fiscalizar o cumprimento da própria legislação ambiental no que se refere ao uso e ocupação do território em fundos de vale. Este procedimento é essencial para o equilíbrio da bacia hidrográfica que corta a FEENA e, conseqüentemente, para a estabilidade do relevo da área.

\section{BIBLIOGRAFIA}

BRASIL. DNAEE. Divisão de Controle de Recursos Hídricos. Glossário de Termos Hidrológicos. Brasília, 1983.

CERON, A.O.; DINIZ, J.A.F. O Uso de Fotografias Aéreas na Identificação das Formas de Utilização Agrícola da Terra. Revista Brasileira de Geografia. Rio de Janeiro, n.2, ano XXVIII, junho/1966. p.161172.

CHRISTOFOLETTI, A. Análise de Sistemas em Geografia. São Paulo: Hucitec, 1979. 106 p. (Geografia, teoria e realidade).

CHRISTOFOLETTI, A. Modelagem de Sistemas Ambientais. São Paulo: Edgard Blücher, 1991. 236 p.

\section{CUNHA, C.M.L. A Cartografia do Relevo no con-}

texto da Gestão Ambiental. 2001. Tese (Doutorado em Geociências e Meio Ambiente) - IGCE, UNESP, Rio Claro, 2001.

CUNHA, C.M.L. Quantificação e mapeamento das perdas do solo por erosão com base na malha fundiária. 1997. Dissertação (Mestrado em Geografia) - IGCE,UNESP, Rio Claro, 1997.

HOWARD, A.D. Equilíbrio e dinâmica dos Sistemas Geomorfológicos. Notícias Geomorfológicas, Campinas, 13 (26), 3-20, 1973.

INSTITUTO FLORESTAL; Secretária de Meio Ambiente. Plano de Manejo da Floresta Estadual Edmundo Navarro de Andrade. Vol.1. Rio Claro: IF/SMA, 2005.

IPT. Instituto de Pesquisas Tecnológicas do Estado de São Paulo. Mapa Geológico do Estado de São Paulo. Nota Explicativa. São Paulo: IPT, 1981.

MACHI, D.A. Análise do relevo da Floresta Estadual Edmundo Navarro de Andrade (Rio Claro - SP) e circunvizinhanças: subsidio para a avaliação da área de entorno. Trabalho de Graduação - IGCE, UNESP, Rio Claro, 2005.

OLIVEIRA, J.B.; PRADO,H. Levantamento Pedológico Semi Detalhado do estado de São Paulo. Quadrícula São Carlos. Memorial Descritivo. Boletim Técnico. Campinas, Instituto Agronômico, $n^{0} 101$, 1984.

TRICART, J. Principes et méthodes de lá geomorphologie. Paris: Masson, 1965.

VERSTAPEN, H.T.; ZUIDAM, R.A. van ITC System of geomorphology survey. Netherlands, Manuel ITC Textbook, Vol. VII, Chapter VII, 1975. 